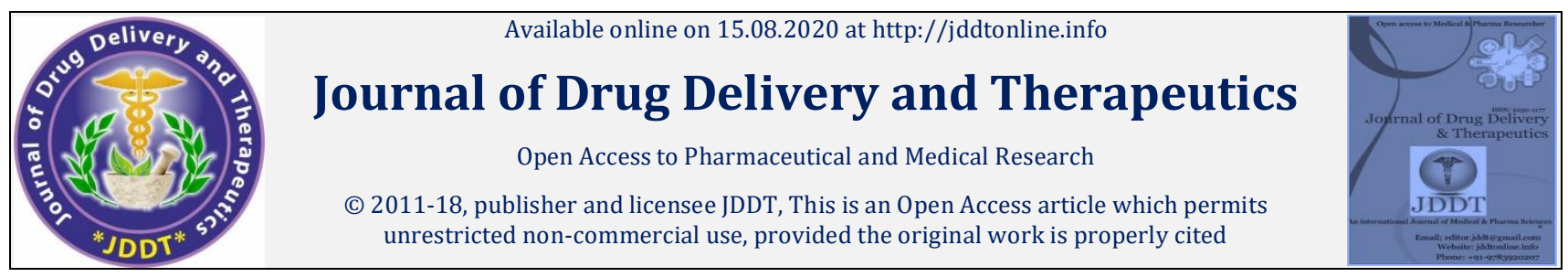

Open 1 Access

Research Article

\title{
Formulation, Development and Evaluation of Chewable Bi-layered Tablets for Treating Gastro Esophageal Reflux Disease
}

\author{
*Ankur Vasoya, Sunil Kumar Shah, C K Tyagi, Prabhakar Budholiya, Harish Pandey \\ Department of Pharmaceutics, College of Pharmacy, Sri Satya Sai University of Technology \& Medical Sciences, Sehore, Madhya Pradesh, India
}

\begin{abstract}
The purpose of this research work was to formulate raft-forming chewable bilayer tablets of sodium alginate using a raft-forming agent along with gas-generating agents. Tablets were prepared by wet granulation and evaluated for raft strength, acid neutralization capacity, weight variation, \% drug content, thickness, hardness, friability and in vitro drug release. Various raft-forming agents were used in preliminary screening. The amount of sodium alginate, amount of calcium carbonate and amount sodium bicarbonate were selected as variables. Raft strength, acid neutralization capacity and drug release at $30 \mathrm{~min}$ were selected as responses.Tablets containing sodium alginate were having maximum raft strength as compared with other raft-forming agents. Acid neutralization capacity and in vitro drug release of all factorial batches were found to be satisfactory. Prepared tablets were found to be pharmaceutically equivalent to the marketed product. It was concluded that raft-forming chewable bilayer tablets prepared using an optimum amount of sodium alginate, calcium carbonate and sodium bicarbonate could be an efficient dosage form in the treatment of gastro oesophageal reflux diseases.
\end{abstract}

Keywords: Chewable bilayer tablet, Sodium alginate, Raft forming agent, Acid Neutralizing capacity

Article Info: Received 12 June 2020; Review Completed 19 July 2020; $\quad$ Accepted 28 July 2020; Available online 15 August 2020

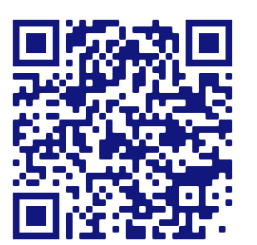

Cite this article as:

Vasoya A, Shah SK, Tyagi CK, Budholiya P, Pandey H, Formulation, Development and Evaluation of Chewable Bi-layered Tablets for Treating Gastro Esophageal Reflux Disease, Journal of Drug Delivery and Therapeutics. 2020; 10(4-s):92-99 http://dx.doi.org/10.22270/jddt.v10i4-s.4224

Ankur Vasoya, Department of Pharmaceutics, College of Pharmacy, Sri Satya Sai University of Technology \& Medical Sciences, Sehore, Madhya Pradesh, India.

\section{INTRODUCTION}

By novel drug delivery system, continuous delivery of the drug at a predictable kinetic over an extended period of time can be achieved. The advantage of this system includes reduction in the drug related side effects which is due to controlled therapeutic blood level instead of oscillating blood level. Another advantage is improved patient compliance because of reduced dosing frequency and reduction of total dose of the drug which is to be administered 1 . Gastro retentive drug delivery system (GRDDS) is a site specific delivery system. It delivers the drug either in stomach or in intestine. The drug delivery is obtained by retention of dosage form in stomach and the drug is released in a controlled manner to the specific site either in stomach, duodenum or in intestine ${ }^{2}$.Gastro-oesophageal reflux disease (GERD) is an ongoing condition in which the contents of the stomach come back into the oesophagus (the tube that carries food from the mouth to the stomach). Doctors call this "acid reflux." GERD often causes heartburn, a burning feeling in the chest and throat. Heartburn may happen many times a week, especially after eating or at night. GERD can also cause cough or have asthma symptoms. It can also make your voice sound hoarse and raspy. Various treatment options available for GERD are taking medicines like antacids, $\mathrm{H} 2$ antagonist, proton pump inhibitor, etc.; surgery to strengthen the barrier between the stomach and the oesophagus may be a treatment option for acid reflux and endoscopic treatments help strengthen the muscle that keeps food and acid from going up into the oesophagus.Raftforming anti-reflux preparations are generally used in the treatment of gastric acid-related disorders, especially GERD, heartburn and oesophagitis ${ }^{3}$. Raft-forming anti-reflux preparations form a viscous, gelatinous neutral layer or barrier on the top of the gastric acid contents. The floating barrier remains located at the lower oesophageal sphincter (LES) and prevents the acidic gastric content from getting refluxed into the oesophagus and provides symptomatic relief to GERD patients. Since this barrier floats on the surface of the stomach content like a raft on water, the barrier is called a raft and the formulations are called as "raft-forming anti-reflux preparations". The unique mechanism of action to provide relief in symptomatic GERD separates raft-forming anti-reflux preparations from traditional antacids and other therapeutic classes for treatment of GERD ${ }^{3-5}$. A raft-forming formulation requires 
sodium or potassium bicarbonate; in the presence of gastric acid, the bicarbonate is converted to carbon dioxide, which becomes entrapped within the gel precipitate, converting it into foam, which floats on the surface of the gastric contents. The antacid components contained in formulations provide a relatively $\mathrm{pH}$-neutral barrier 3,6 . Calcium carbonate can be used as an antacid as well as a raft-strengthening agent. It releases calcium ions, which react with alginate and form an insoluble gel7,8. Various polymers, especially different polysaccharides, have been used in various research works. Alginic acid, alginates and pectin are the most widely used raft- forming agents ${ }^{4}$. Other polysaccharides are also being used, which include guar gum, locust bean gum, carrageenan, pectin and isapgol4,6,9.Chewable tablets are designed for use by the children and such persons who may have difficulty in swallowing the tablets ${ }^{10}$.These are intended to be chewed in the mouth prior to swallowing and are not intended to be swallowed intact ${ }^{11}$. Additionally, chewable tablets facilitate more rapid release and hence more rapid absorption of active ingredients and provide quick onset of action ${ }^{12}$. Hence it was decided to formulate chewable bilayer tablet for the treatment of gastro esophageal reflux disease (GERD).

\section{MATERIAL AND METHODS}

\section{Material}

Sodium alginate was obtained from FMC Biopolymer, Sodium Bicarbonate from Ava chemicals, and Calcium Carbonate from Scora S.A as gift sample. Macrogol 20000 was procured from Sanyo chemicals, Kollidon VA 64 from BASF, Aspartame and Acesulfame K from Pioma chemicals. Peppermint Flavor and Magnesium Stearate was purchased from Sunshine chemicals and Color Carmosine Lake was collected from Emichem.

\section{Methods}

\section{Preparation of blend for pink layer}

All ingredients namely Soium alginate, Sodium bicarbonate, Calcium carbonate/Scoralite LL-100, Macrogol 20000, Kollidon VA 64, Aspartame, Acesulfame K and Pearlitol 160 C/Pearlitol SD200 were weighed separately. Sodium alginate, Sodium bicarbonate, Calcium carbonate/ Scoralite LL-100, Macrogol 20000, Kollidon VA 64, Aspartame, Acesulfame K and Pearlitol $160 \mathrm{C} /$ Pearlitol SD200 were sifted through sieve \# 40. Peppermint flavor and Color carmosine lake were sifted through sieve \# 60 and \# 100 respectively.Dry mixing of all above ingredients was carried out in octagonal blender for 10 minutes. Magnesium stearate was sifted through sieve \# 60 and mixed with the above blend for 3 minutes. It was ensured that blending was done properly. The blend was subjected to various tests for physical parameters. The composition of blend for pink layer is shown in table 1.

Table 1: Composition for blend of pink layer

\begin{tabular}{|c|c|c|c|c|c|c|c|c|c|}
\hline \multirow{2}{*}{$\begin{array}{l}\text { Sr. } \\
\text { no. }\end{array}$} & \multirow{2}{*}{ Ingredients } & \multicolumn{8}{|c|}{ Qty/Tab (mg) } \\
\hline & & T1 & T2 & T3 & T4 & T5 & T6 & T7 & T8 \\
\hline 1 & Sodium Alginate & 250.00 & 250.00 & 250.00 & 250.00 & 250.00 & 250.00 & 250.00 & 250.00 \\
\hline 2 & Sodium Bicarbonate & 106.5 & 106.5 & 106.5 & 106.5 & 106.5 & 106.5 & 106.5 & 106.5 \\
\hline 3 & Calcium Carbonate & 60.00 & 60.00 & 60.00 & 55.00 & 60.00 & 60.00 & - & 60.00 \\
\hline 4 & Macrogol 20000 & 60.00 & 70.00 & 55.00 & 55.00 & 50.00 & 50.00 & 50.00 & - \\
\hline 5 & Kollidon VA 64 & 15.00 & 15.00 & 20.00 & 15.00 & 15.00 & 25.00 & 25.00 & 25.00 \\
\hline 6 & Aspartame & 30.00 & 25.00 & 25.00 & 25.00 & 30.00 & 30.00 & 30.00 & 30.00 \\
\hline 7 & Acesulfame K & 3.00 & 3.00 & 3.00 & 3.00 & 3.00 & 3.00 & 3.00 & 3.00 \\
\hline 8 & Pearlitol 160 C/SD 200* & 175.5 & 164.75 & 184.0 & 84.85 & 206.75 & 196.75 & 256.75 & 196.75 \\
\hline 9 & Peppermint Flavor & 5.00 & 5.00 & 5.00 & 5.10 & 8.00 & 8.00 & 8.00 & 8.00 \\
\hline 10 & Color Carmosine Lake & 1.00 & 0.75 & 1.50 & 0.45 & 0.75 & 0.75 & 0.75 & 0.75 \\
\hline 11 & Magnesium Stearate & 15.00 & 15 & 15.00 & 15.00 & 15.00 & 15.00 & 15.00 & 15.00 \\
\hline & Total weight & 720.00 & 720.00 & 720.00 & 720.00 & 720.00 & 720.00 & 720.00 & 720.00 \\
\hline
\end{tabular}

\section{Preparation of blend for white layer}

All ingredients namely calcium carbonate/Scoralite LL-100, macrogol 20000, aspartame, acesulfame k, kollidon va 64 and pearlitol $160 \mathrm{c}$ /pearlitol SD 200 were weighed separately. calcium carbonate/Scoralite LL-100, Macrogol 20000, aspartame, acesulfame K, kollidon VA 64 and Pearlitol 160 C/Pearlitol SD 200 were sifted through sieve
\#.40. Peppermint flavor was sifted through sieve \# 60. Dry mixing of all above ingredients was carried out in octagonal blender for 10 minutes. Magnesium stearate was sifted through sieve \# 60 and mixed with the above blend for 3 minutes. It was ensured that blending was done properly. The blend was subjected to various tests for physical parameters. The composition of blend for white layer is shown in table 2 . 
Table 2: Composition for blend of white layer

\begin{tabular}{|c|c|c|c|c|c|c|c|c|c|}
\hline \multirow{2}{*}{$\begin{array}{l}\text { Sr. } \\
\text { no. }\end{array}$} & \multirow{2}{*}{ Ingredients } & \multicolumn{8}{|c|}{ Qty/Tab (mg) } \\
\hline & & T1 & T2 & T3 & T4 & T5 & T6 & T7 & T8 \\
\hline 1 & Calcium Carbonate & 127.5 & 127.5 & 127.5 & 127.5 & - & - & - & - \\
\hline 2 & Scoralite LL-100 & - & - & - & - & 127.5 & 127.5 & 187.5 & 127.5 \\
\hline 3 & Macrogol 20000 & 55.00 & 50.00 & 35.00 & 35.00 & 30.00 & 30.00 & 30.00 & - \\
\hline 4 & Aspartame & 25.00 & 20.00 & 25.00 & 20.00 & 15.00 & 15.00 & 15.00 & 15.00 \\
\hline 5 & Acesulfame $\mathrm{K}$ & 3.00 & 3.00 & 3.00 & 3.00 & 3.00 & 3.00 & 3.00 & 3.00 \\
\hline 6 & Kollidon VA 64 & - & 10.00 & 10.00 & 10.00 & 15 & 18.00 & 12.00 & 11 \\
\hline 7 & Pearlitol 160 C/SD 200* & 396.5 & 386.5 & 407.0 & 201.5 & 418.5 & 401.5 & 341.5 & 402.5 \\
\hline 8 & Peppermint Flavor & 3.00 & 3.00 & 2.50 & 3.00 & 5.00 & 5.00 & 5.00 & 5.00 \\
\hline 9. & Magnesium Stearate & 10.00 & 10.00 & 10.00 & 10.00 & 10.00 & 10.00 & 10.00 & 10 \\
\hline & Total weight & 610.00 & 610.00 & 610.00 & 610.00 & 610.00 & 610.00 & 610.00 & 610.00 \\
\hline
\end{tabular}

\section{Preparation of chewable bilayer tablet}

Compression method was used to prepare chewable bilayer tablet. Both blends were compressed into tablets on a 27 station rotary Bilayer tablet compression machine using 14.5 $\mathrm{mm}$ round shape flat beveled edged punches with break-line on upper punch.

\section{Evaluation of the blends and tablets ${ }^{13-15}$}

\section{Analysis of physicochemical parameters}

\section{Physical evaluation of lubricated blend}

The lubricated blends of both the layers were subjected to the following physical parameter testing in all the batches prepared.

\section{Bulk density}

Bulk density is defined as a mass of a powder divided by the bulk volume. A blend (20 gm) was introduced in $100 \mathrm{ml}$ graduated cylinder. The volume of the material was noted on graduated cylinder. The bulk density was calculated by the formula given below;

\section{Bulk density $\left(\rho_{0}\right)=M / V_{0}$} powder

Where, $\mathrm{M}=$ mass of the powder, $\mathbf{V}_{\mathbf{0}}=$ volume of the

\section{Tapped density}

The mechanical tapping of the cylinder was carried out at a rate of 300 drops per minute for 500 times from 3" height and the tapped volume $\left(\mathrm{V}_{\mathrm{f}}\right)$ was noted. The tapped density was calculated in $\mathrm{gm} / \mathrm{cm}^{3}$ by the formula

\section{Tapped density $\left(\rho_{t}\right)=M / V f$}

Where, $\mathrm{M}=$ weight of sample powder taken, $\mathrm{Vf}=$ tapped volume

\section{Compressibility index}

The bulk density and tapped density were measured and compressibility index was calculated using the formula.

$$
\text { C.I. }=\left\{\left(\rho_{\mathrm{t}}-\rho \mathrm{o}\right) / \rho \mathrm{t}\right\} \times \mathbf{1 0 0}
$$

Where, $\rho \mathrm{t}=$ tapped density, $\rho$ o = bulk density

\section{Hausner ratio}

Tapped density and bulk density were measured and the Hausner ratio was calculated using the formula

\section{Hausner Ratio $=\rho t / \rho o$}

Where, $\rho \mathrm{t}=$ tapped density, $\rho \mathrm{o}=$ bulk density

\section{Loss on drying (LOD)}

The LOD of wet sample is often determined by the use of moisture balance, which has a heat source for rapid heating and a scale calibrated in \% LOD. A weighed sample is placed on the balance and allowed to dry until it reached constant weight. The water lost by evaporation is read directly from percent LOD scale.

\section{$\%$ Fines through 60 \#}

The particle size distribution was carried by sieve analysis and $\%$ fines were determined by calculating weight of granules passed through 60 \#.

\section{Angle of repose}

Angle of repose is a characteristic related to interparticulate friction or resistance to movement between particles. $20 \mathrm{gm}$ of blend was passed through resperograph. Angle of repose was determined by measuring the height of the cone of the powder and calculating the angle of repose from following formula.

$$
\Theta=\tan ^{-1}(h / r)
$$

Where, $\mathrm{h}=$ height of pile,

$$
r=\text { radius of pile }
$$

\section{Physical evaluation of tablets}

\section{Description}

Color and shape of the tablets were observed by visual observation.

\section{Average weight of tablets}

Twenty tablets were dedusted and weighed accurately.

\section{Thickness}

Five tablets were randomly selected and thickness of the tablets was measured by previously calibrated vernier caliper. 


\section{Hardness test}

Five tablets were randomly selected. One tablet at a time was placed in the hardness tester which was already set to zero. Pressure was applied, till the tablet broke. Reading on the Schreudinger Hardness tester i.e. the hardness of tablets was noted down in Newtons.

\section{Friability test}

Average weight of tablet was less than $0.65 \mathrm{~g}$, hence a sample of whole tablets corresponding to about $6.5 \mathrm{~g}(\mathrm{X})$ was taken. These tablets were added to the friability test apparatus which was already set to $25 \mathrm{rpm}$. After completion of 4 minutes, tablets were removed and dedusted. Weight of the tablets was noted down (Y).

$\%$ Friability was calculated by following formula:

$$
\% \text { Friability }=X-Y / X * 100
$$

\section{Disintegration test (Only for white layer)}

The disintegration assembly was suspended in the specified liquid medium in a $1000 \mathrm{ml}$ beaker. The volume of liquid was taken such that when the assembly was in highest position the wire mesh was at least $25 \mathrm{~mm}$ below the surface of the liquid and when the assembly was in lowest position the wire mesh was at least $25 \mathrm{~mm}$ above the bottom of the beaker. One tablet was placed into each of the tube of the assembly and disk was added to each tube. The apparatus was operated for specified time and temperature at $37 \pm 2^{\circ} \mathrm{C}$ Time for complete disintegration of tablet was noted down.

\section{Uniformity of weight}

20 tablets were randomly selected, dedusted and weighed individually. \% weight variation from actual average weight of tablet was calculated using the following formula:

$\%$ Weight variation from actual average weight of tablet $=$

100*(Individual tablet weight- Avg. weight)/ Avg. weight of tablet

Evaluation of parameters related to raft and acid neutralizing capacity

\section{Raft strength 14,16}

To check for raft formation properties and the appearance of the rafts, four crushed tablets (total $1 \mathrm{gm}$ sodium alginate) were mixed with $20 \mathrm{ml}$ of water and poured into a $250 \mathrm{ml}$ beaker containing $150 \mathrm{ml} 0.1 \mathrm{M} \mathrm{HCl}$ at $37^{\circ} \mathrm{C}$. The ability to form a coherent foamy floating gel "raft" on the surface of the acid over 30 minutes was observed.

\section{Raft volume and raft weight ${ }^{16}$}

Rafts were formed and developed for $30 \mathrm{~min}$ in glass beakers, as above, but without the inclusion of a wire probe. Each beaker used for raft formation was preweighed (W1). The position to which the top of each raft reached was marked on the outside of the beaker. The total weight of the beaker and contents was obtained after raft development $(W 2)$. The raft was then removed from the beaker by carefully decanting the subnatant liquid and tipping the raft into a pre-tared plastic weighing boat. This was left to stand for $30 \mathrm{~s}$, excess subnatant liquid was drained off and the raft was weighed (W3). Remaining liquid was removed from the inside of the beaker with a paper towel and it was then refilled with water to the marked position and weighed (W4). The volume of each raft was then calculated from the formula:

\section{Raft Volume =(W4 -W1) $-(\mathrm{W} 2-\mathrm{W} 1-\mathrm{W} 3)$}

Where raft volume is measured in $\mathrm{ml}$. and all weights are measured in gm.

The formula assumes that the density of the subnatant liquid is the same as that of water.

\section{Raft thickness and time for raft formation 17}

The time required for all the alginate material to rise to the top half of a $250 \mathrm{ml}$ beaker, containing $125 \mathrm{ml} \mathrm{HCl}$ at $37^{\circ} \mathrm{C}$ was measured. The beaker was then placed in a water bath to maintain the temperature and 20 min later the thickness of the raft produced was measured at 4 places and the results were averaged.

\section{pH measurement}

The in vitro pH profiles for the tablets were measured in and below the raft and measured time to maintain elevated $\mathrm{pH}$ in raft and in solution.

\section{Acid neutralizing capacity (ANC) ${ }^{18}$}

20 tablets were weighed, and the average tablet weight was determined. Tablets were ground to a fine powder, mixed to obtain a uniform mixture. An accurately weighed quantity of it was transfered, equivalent to the minimum labeled dosage, to a $250-\mathrm{mL}$ beaker. $50 \mathrm{~mL}$ of water was added, and mixed on the magnetic stirrer for 1 minute. $30.0 \mathrm{~mL}$ of $1.0 \mathrm{~N}$ hydrochloric acid was pippetted out into the Test Preparation while continuously stirring with the magnetic stirrer for 10 minutes, accurately timed, after the addition of the acid. Stirring was discontinued briefly, and without delay, gum base was removed from the beaker using a long needle. Promptly the needle was rinsed with $20 \mathrm{~mL}$ of water, collecting the washing in the beaker, and resuming stirring for 5 minutes, accurately timed, then beginning titration immediately, and in a period not to exceed an additional 5 minutes. Excess Hydrochloric acid was titrated with $0.5 \mathrm{~N}$ sodium hydroxide to attain a stable (for 10 to 15 seconds) $\mathrm{pH}$ of 3.5. The number of $\mathrm{mEq}^{+}$of acid consumed by the tablet tested was calculated by the formula.

\section{Total $\mathrm{mEq}^{+}=(30 \times \mathrm{N} \mathrm{HCl})-(\mathrm{V} \mathrm{NaOH} \times \mathrm{N} \mathrm{NaOH})$}

N HCI $=$ Normality of $\mathrm{HCl}, \quad \mathrm{V} \mathrm{NaOH}=$ Volume of $\mathrm{NaOH}$ required, $\mathrm{N} \mathrm{NaOH}=$ Normality of $\mathrm{NaOH}$

\section{RESULTS}

Results of preliminary studies and characterizations of API

The preliminary studies of API were complying with the prescribed standard of quality. Results of preliminary studies are recorded in Table 3. 
Table 3: Results of preliminary studies of API

\begin{tabular}{|c|c|c|}
\hline Sr. No. & Tests & Results \\
\hline 1. & Description & White to off-White cremish crystalline powder \\
\hline 2. & Solubility & $\begin{array}{c}\text { Practically insoluble in ethanol (95\%), ether, chloroform, and ethanol/water } \\
\text { mixture. } \\
\text { Slowly soluble in water, forming a viscous colloidal solution. }\end{array}$ \\
\hline 3 & Viscosity & $575 \mathrm{mPas}$ \\
\hline 4 & Ph & 7.3 \\
\hline 5 & Particle size through 60 \# & $99.51 \%$ \\
\hline 6 & & Additional tests \\
\hline a. & Sulphated ash & $32.4 \%$ \\
\hline b. & Ash & $19.6 \%$ \\
\hline c. & Calcium & $1.13 \%$ \\
\hline d. & Chlorides & $0.68 \%$ \\
\hline 7. & & Heavy metals tests \\
\hline a. & Total heavy metals & $16 \mathrm{ppm}$ \\
\hline b. & Arsenic (As) & $0.9 \mathrm{ppm}$ \\
\hline c. & Lead $(\mathrm{Pb})$ & $1 \mathrm{ppm}$ \\
\hline $\mathrm{d}$. & Iron $(\mathrm{Fe})$ & $2 \mathrm{ppm}$ \\
\hline 8. & & Microbial Limits \\
\hline a. & Total viable aerobic count & $100^{3} \mathrm{cfu} / \mathrm{g}^{*}$ \\
\hline b. & Escherichia coli & Absent \\
\hline c. & Salmonella & Absent \\
\hline d. & Total bacterial count & $114 \mathrm{cfu} / \mathrm{g}$ \\
\hline
\end{tabular}

\section{Evaluation of marketed product}

Marketed product was evaluated for its physical parameters

Table 4: Physical parameters of marketed product

\begin{tabular}{|l|l|l|l|l|}
\hline $\begin{array}{l}\text { Physical } \\
\text { Parameters }\end{array}$ & Thickness(mm) & Hardness(N) & Weight(gm) & Friability (\%) \\
\hline & 5.55 & 115 & 1.320 & \\
Marketed Product & 5.56 & 135 & 1.326 & 0.2 \\
& 5.51 & 127 & 1.298 & (at 100 RPM) \\
& 5.56 & 146 & 1.322 & \\
\hline
\end{tabular}




\section{Results of formulation batches}

Trials were taken to formulate the chewable tablet which is equivalent to marketed product. Physicochemical parameters and parameters related to Raft of Alginate containing tablet were evaluated. Results of formulation trials are shown in table 5-6.

Table 5: Blend parameters and IPQC parameters of Trial 1-4

\begin{tabular}{|c|c|c|c|c|c|c|c|c|c|}
\hline \multirow[b]{2}{*}{$\begin{array}{l}\text { Sr. } \\
\text { no. }\end{array}$} & \multirow[b]{2}{*}{ Parameter } & \multicolumn{2}{|l|}{ T1 } & \multicolumn{2}{|l|}{ T2 } & \multicolumn{2}{|l|}{ T3 } & \multicolumn{2}{|l|}{ T4 } \\
\hline & & $\begin{array}{l}\text { Pink } \\
\text { layer }\end{array}$ & $\begin{array}{l}\text { White } \\
\text { layer }\end{array}$ & $\begin{array}{l}\text { Pink } \\
\text { layer }\end{array}$ & $\begin{array}{l}\text { White } \\
\text { layer }\end{array}$ & $\begin{array}{l}\text { Pink } \\
\text { layer }\end{array}$ & $\begin{array}{l}\text { White } \\
\text { layer }\end{array}$ & $\begin{array}{l}\text { Pink } \\
\text { layer }\end{array}$ & $\begin{array}{l}\text { White } \\
\text { layer }\end{array}$ \\
\hline \multicolumn{10}{|c|}{ In Process Evaluation } \\
\hline 1 & Unlubricated LOD \% w/w & 0.88 & 1.10 & 0.92 & 1.14 & 0.72 & 1.04 & 1.6 & 1.7 \\
\hline 2 & Lubricated LOD \% w/w & 1.20 & 1.44 & 1.34 & 1.56 & 1.22 & 1.34 & 2.3 & 2.5 \\
\hline 3 & Tapped density (g/ml) & 0.471 & 0.486 & 0.474 & 0.486 & 0.645 & 0.576 & 0.469 & 0.487 \\
\hline 4 & Bulk density $(\mathrm{g} / \mathrm{ml})$ & 0.602 & 0.667 & 0.622 & 0.697 & 0.807 & 0.756 & 0.602 & 0.667 \\
\hline 5 & Compressibility index (\%) & 21.81 & 26.82 & 23.74 & 29.63 & 20.55 & 23.67 & 21.77 & 26.83 \\
\hline 6 & Hausner's Ratio & 1.271 & 1.370 & 1.308 & 1.421 & 1.24 & 1.314 & 1.278 & 1.360 \\
\hline 7 & $\%$ fines through $60 \#$ & 74 & 82 & 84 & 87 & 92 & 84 & 74 & 80 \\
\hline 8 & Angle of repose & 33.3 & 37.0 & 31.0 & 36.4 & 32.3 & 36.8 & - & - \\
\hline \multicolumn{10}{|c|}{ Finished Product evaluation } \\
\hline 1 & Tablet Dimension & \multicolumn{2}{|c|}{$\begin{array}{l}14.52 \text { to } 14.55 \\
\mathrm{~mm}\end{array}$} & \multicolumn{2}{|c|}{$14.53-14.56 \mathrm{~mm}$} & \multicolumn{2}{|c|}{$14.52-14.56 \mathrm{~mm}$} & \multicolumn{2}{|c|}{$14.53-14.56 \mathrm{~mm}$} \\
\hline 2 & Thickness & \multicolumn{2}{|c|}{$5.60-5.70 \mathrm{~mm}$} & \multicolumn{2}{|c|}{$5.60-5.70 \mathrm{~mm}$} & \multicolumn{2}{|c|}{$5.55-5.60 \mathrm{~mm}$} & \multicolumn{2}{|c|}{$5.66-5.70 \mathrm{~mm}$} \\
\hline 3 & Average Weight & \multicolumn{2}{|c|}{$1.342 \mathrm{gm}$} & \multicolumn{2}{|c|}{$1.336 \mathrm{gm}$} & \multicolumn{2}{|c|}{$1.356 \mathrm{gm}$} & \multicolumn{2}{|c|}{$1.356 \mathrm{gm}$} \\
\hline 4 & Hardness & \multicolumn{2}{|c|}{$150-180 \mathrm{~N}$} & \multicolumn{2}{|c|}{$120-150 \mathrm{~N}$} & \multicolumn{2}{|c|}{$120-150 \mathrm{~N}$} & \multicolumn{2}{|c|}{$180-220 \mathrm{~N}$} \\
\hline 5 & Friability & \multicolumn{2}{|c|}{ Failed } & \multicolumn{2}{|c|}{$0.6 \%$} & \multicolumn{2}{|c|}{$0.5 \%$} & \multicolumn{2}{|c|}{$0.06 \%$} \\
\hline 6 & Disintegration Time & \multicolumn{2}{|c|}{ within 5 minutes } & \multicolumn{2}{|c|}{$\begin{array}{l}\text { within } 10 \\
\text { minutes }\end{array}$} & \multicolumn{2}{|c|}{$\begin{array}{l}\text { within } 10 \\
\text { minutes }\end{array}$} & \multicolumn{2}{|c|}{ Not disintegrate } \\
\hline 7 & Lag time & \multicolumn{2}{|c|}{10 minutes } & \multicolumn{2}{|c|}{13 minutes } & \multicolumn{2}{|c|}{10 minutes } & More $t$ & 1 hour \\
\hline
\end{tabular}

Table 6: Blend parameters and IPQC parameters of trial 5-8

\begin{tabular}{|c|c|c|c|c|c|c|c|c|c|}
\hline \multirow{2}{*}{$\begin{array}{l}\text { Sr. } \\
\text { no. }\end{array}$} & \multirow[b]{2}{*}{ Parameter } & \multicolumn{2}{|l|}{ T5 } & \multicolumn{2}{|l|}{ T6 } & \multicolumn{2}{|l|}{ T7 } & \multicolumn{2}{|l|}{ T8 } \\
\hline & & $\begin{array}{l}\text { Pink } \\
\text { layer }\end{array}$ & $\begin{array}{l}\text { White } \\
\text { layer }\end{array}$ & $\begin{array}{l}\text { Pink } \\
\text { layer }\end{array}$ & $\begin{array}{l}\text { White } \\
\text { layer }\end{array}$ & $\begin{array}{l}\text { Pink } \\
\text { layer }\end{array}$ & $\begin{array}{l}\text { White } \\
\text { layer }\end{array}$ & $\begin{array}{l}\text { Pink } \\
\text { layer }\end{array}$ & $\begin{array}{l}\text { White } \\
\text { layer }\end{array}$ \\
\hline \multicolumn{10}{|c|}{ In Process Evaluation } \\
\hline 1 & Unlubricated LOD \% w/w & 1.08 & 1.22 & 1.11 & 1.24 & 1.06 & 1.31 & 0.8 & 1.0 \\
\hline 2 & Lubricated LOD \% w/w & 1.33 & 1.41 & 1.34 & 1.44 & 1.25 & 1.49 & 1.15 & 1.24 \\
\hline 3 & Tapped density (g/ml) & 0.734 & 0.783 & 0.734 & 0.783 & 0.735 & 0.783 & 0.807 & 0.786 \\
\hline 4 & Bulk density $(\mathrm{g} / \mathrm{ml})$ & 0.625 & 0.693 & 0.624 & 0.694 & 0.624 & 0.716 & 0.690 & 0.696 \\
\hline 5 & Compressibility index (\%) & 14.95 & 11.92 & 14.96 & 11.92 & 14.95 & 10.2 & 13.88 & 11.90 \\
\hline 6 & Hausner's Ratio & 1.17 & 1.14 & 1.17 & 1.14 & 1.18 & 1.07 & 1.34 & 1.12 \\
\hline 7 & $\%$ fines through $60 \#$ & $61 \%$ & $57 \%$ & $64 \%$ & $59 \%$ & $64 \%$ & $60 \%$ & $77 \%$ & $81 \%$ \\
\hline 8 & Angle of repose & 27.6 & 26.4 & 25.8 & 24.5 & 26.2 & 24.1 & 25.7 & 24.2 \\
\hline \multicolumn{10}{|c|}{ Finished Product evaluation } \\
\hline 1 & Tablet Dimension & \multicolumn{2}{|c|}{$14.52-14.53 \mathrm{~mm}$} & \multicolumn{2}{|c|}{$14.52-14.53 \mathrm{~mm}$} & \multicolumn{2}{|c|}{$14.51-14.53 \mathrm{~mm}$} & \multicolumn{2}{|c|}{$14.51-14.53 \mathrm{~mm}$} \\
\hline 2 & Thickness & \multicolumn{2}{|c|}{$5.60-5.70 \mathrm{~mm}$} & \multicolumn{2}{|c|}{$5.60-5.70 \mathrm{~mm}$} & \multicolumn{2}{|c|}{$5.60-5.70 \mathrm{~mm}$} & \multicolumn{2}{|c|}{$5.60-5.70 \mathrm{~mm}$} \\
\hline 3 & Average Weight & \multicolumn{2}{|c|}{$1.335 \mathrm{gm}$} & \multicolumn{2}{|c|}{$1.315 \mathrm{gm}$} & \multicolumn{2}{|c|}{$1.294 \mathrm{gm}$} & \multicolumn{2}{|c|}{$1.324 \mathrm{gm}$} \\
\hline 4 & Hardness & \multicolumn{2}{|c|}{$120-150 \mathrm{~N}$} & \multicolumn{2}{|c|}{$120-150 \mathrm{~N}$} & \multicolumn{2}{|c|}{$120-150 \mathrm{~N}$} & \multicolumn{2}{|c|}{$120-150 \mathrm{~N}$} \\
\hline 5 & Friability & \multicolumn{2}{|l|}{$0.3 \%$} & \multicolumn{2}{|l|}{$0.16 \%$} & \multicolumn{2}{|l|}{$0.15 \%$} & \multicolumn{2}{|l|}{$0.11 \%$} \\
\hline 6 & Disintegration Time & \multicolumn{2}{|c|}{$\begin{array}{l}\text { within } 25 \\
\text { minutes }\end{array}$} & \multicolumn{2}{|c|}{$\begin{array}{l}\text { within } 25 \\
\text { minutes }\end{array}$} & \multicolumn{2}{|c|}{$\begin{array}{l}\text { within } 25 \\
\text { minutes }\end{array}$} & \multicolumn{2}{|c|}{ within 25 minutes } \\
\hline 7 & Lag time & \multicolumn{2}{|c|}{20 minutes } & \multicolumn{2}{|c|}{35 minutes } & \multicolumn{2}{|c|}{35 minutes } & $35 \mathrm{mir}$ & \\
\hline
\end{tabular}




\section{Evaluation of raft related parameters}

In Trial 06, all physical parameters and raft related parameters were found to be similar to marketed product and ANC was same as marketed product. Hence, trial 06
(T6) was found to be optimized batch and this formula was used for further studies. The comparison of raf related parameters between marketed product and trial 06 is shown in table 7.

Table 7: Parameters Related to Raft of marketed product and Trial 06

\begin{tabular}{|l|l|l|}
\hline \multirow{2}{*}{ Parameters } & Results \\
\cline { 2 - 3 } & Marketed product & T6 \\
\hline Raft Strength & $13.2 \mathrm{gm}$ & $12.7 \mathrm{gm}$ \\
\hline Raft Thickness & $3.86 \mathrm{~cm}$ & $3.75 \mathrm{~cm}$ \\
\hline Raft Weight & $8.2 \mathrm{gm}$ & $7.8 \mathrm{gm}$ \\
\hline Raft Volume & $55.1 \mathrm{ml}$ & $50.1 \mathrm{ml}$ \\
\hline pH in Raft \& in solution & $5.2 \& 2.1$ & $5.0 \& 1.9$ \\
\hline ANC & $17 \mathrm{mEq}^{+}$ & $16 \mathrm{mEq}^{+}$ \\
\hline
\end{tabular}

\section{Mouth feeling effect study}

Table 8: Comparison of mouth feeling effect between batches T6 and marketed product.

\begin{tabular}{|l|l|l|l|l|l|}
\hline Mouth effect & $\begin{array}{l}\text { Tooth } \\
\text { Packing }\end{array}$ & Mouth feel & Sticking & Taste & Overall \\
\hline Batch & Very slight & $\begin{array}{l}\text { Drier, tablet broke up } \\
\text { quickly }\end{array}$ & $\begin{array}{l}\text { Slightly } \\
\text { up quickly }\end{array}$ & Pleasant, mint & Ok-acceptable \\
\hline $\begin{array}{l}\text { Marketed } \\
\text { product }\end{array}$ & Nil & Not happening & Pleasant, mint & $\begin{array}{l}\text { Good- } \\
\text { acceptable }\end{array}$ \\
\hline
\end{tabular}

It was found that marketed product was not having any tooth packing and sticking effect and taste was also pleasant. But T6 tablet was having slight tooth packing and sticking effect but it was acceptable. The results suggested that Macrogol 20000 is needed for optimum formulation.

\section{SUMMARY}

The purpose of the present study was to develop and characterize a generic product of alginate raft forming formulation. Patents related to brand product were examined and a manufacturing formula was conceived.Direct compression technology was chosen to develop a finished pharmaceutical product out of the envisaged formula. Direct compression technology was more cost effective and time saving when compared to wet granulation method. Procurement of excipients by product leaflet and label claim of marketed product and HPLC studies of marketed product in which both the layers were separated and analyzed. Results of these studies suggested that Sodium alginate and Sodium bicarbonate were included in pink layer and Calcium Carbonate was included in to both layers.Various formulation trials were taken, Pearlitol SD 200 was used to improve flow properties and Scoralite LL-100 was used to improve compressibility of white layer.All physiochemical parameters and parameters related to raft were compared with marketed product. It was concluded that all parameters were matched with marketed product.When, all quantity of Calcium Carbonate was incorporated in to white layer, raft strength decreased and acid neutralizing capacity increased.Acid neutralizing capacity was found to be identical with marketed product.Macrogol 20000 was having effect on mouth feeling. But it did not affect ANC and raft strength. Tablet without having Macrogol 20000 did not have good mouth feel and tooth packing effect.

\section{CONCLUSION}

Formulation of chewable bi-layer tablet which contained alginate was successfully formulated which had attributes such as Sustained and immediate effect, Floats on stomach for 6 to 8 hours, improved patient compliance, stable and economical, comparable to marketed product. Based on various studies carried out in the formulation trials, it was concluded that the direct compression is the preferred technology for the preparation of chewable bi-layer tablet for treating GERD. Scoralite LL-100 is required for good compressibility of white layer which is heavy grade of Calcium carbonate. Prepared tablets showed a similar physical parameters and parameters related to raft when compared to the marketed product. Macrogol 20000 is required for good mouth feeling.Prepared tablets were found to be pharmaceutically equivalent to the marketed product.

\section{REFERENCES}

1. Vikas K, Arvind S, Ashish S, Gourav J, Vipasha D. Recent advances in ndds (novel drug delivery system) for delivery of anti-hypertensive drugs. Int J Drug Dev Res. 2011; 3(1):252-9.

2. Bhavsar DN, Varde NM,Sini SC, Shah VH. Advances in grdds: raft forming system a review J. Drug Deliv Ther. 2012; 2(5):123-128.

3. Mandel KG, Daggy BP, Jacoby HI, Brodie DA. Review article: alginate raft formulations in the treatment of heartburn and acid reflux. Aliment Pharmacol Ther. 2000; 14:669-90.

4. Kapadia CJ, Mane VB. Raft forming agents: Antireflux formulation. Drug Dev Ind Pharm. 2007; 33:1350-61. 
5. Washington N, Wilson CG, Greaves JL, Danneskiold SP. An investigation into the floating behaviour of a pectin-containing anti-reflux formulation by means of gamma scintigraphy. Scand J Gastroenterol. 1988; 23:920-4

6. Waterhouse ET, Washington C, Washington N. An investigation into efficacy of pectin based anti-reflux formulation-Aflurax. Int J Pharm. 2000; 209:7985.

7. Hampson FC, Jolliffe IG, Bakhtyari A, Taylor G, Sykes J, Johnstone LM, et al. Alginate-antacid combinations: Raft formation and gastric retention studies. Drug Dev Ind Pharm. 2010; 36:614-23.

8. Johnson FA, Craig DQ, Mercer AD, Chauhan S. The effects of alginate molecular structure and formulation variables on the physical characteristics of alginate raft systems. Int J Pharm. 1997; 159:35-42.

9. Mandelkar SV, Marathe SS, Devrajan PV. A novel raft-forming suspension using a natural dietary fibre. Int J Pharm. 1997; 148:117-21.

10. Kanaka DN, Prameela Rani A, RadhaMadhav B, Sai Mrudula B, Formulation and evaluation of pulsatile drug delivery system of salbutamol sulphate for chronotherapy of asthama. Int Pharm Sci Bio Tech. 2010; 11:20-24.
11. Swati J, Mahesh G, Dhaval B, Bhanudas K, Aniruddha C Formulation design and evaluation of chewable tablets containing h2 blocker. Int J Res Pharm Sci. 2010; 13:282-289.

12. Kathiresan K, Vijin P, Moorthi C, ManavalanR, Formulation and evaluation of loratadine chewable tablets. Res J Pharm. 2010; 14:763-774.

13. United States Pharmacopoeia 32, national formulary 24, 12601, Twinbrook Parkway, Rockville, MD 20852, 2006.

14. British Pharmacopeia, published by The Stationery Office on behalf of the Medicines and Healthcare Products Regulatory Agency (MHRA), 2007; 1384-1385.

15. Prajapati ST, Mehta AP, Modhia IP, Patel CN. Formulation and optimisation of raft-forming chewable tablets containing $\mathrm{H} 2$ antagonist. Int J Pharm Invest. 2012; 2(4):176-182

16. Hampson FC, Farndale A, Strugala V, Sykes J, Jolliffe IG Dettmar PW, Alginate rafts and their characterization. Int Pharm. 2005; 294:137-147.

17. Washington N, Washington C, Wilson CG. Gastric distribution and residence time of two anti-reflux formulations. Int J Pharm. 1987; 39: 163-171.

18. https://www.webmd.com/heartburngerd/guide/understanding-gerd-treatment\#1 